\title{
A Personal Reflection on the Computer Assisted Instruction: Online Learning Tutoring
}

\author{
Akin Metli \\ Bilkent Erzurum Laboratory School (BELS) \\ Erzurum, Turkey
}

\begin{abstract}
This paper presents personal reflections on the effectiveness and the utilization of computer assisted instruction (CAI) in the basic $R$ statistics and graphing sessions on an online learning tutoring website. My personal reflection is focused on the critical analysis of CAI as well as my personal reflective experiences in tutoring sessions on statistics. This paper presents learner experiences with regards to the pros and cons of CAI and a personal approach to the utilization of CAI as a teacher. The reflection paper concludes that CAI can be a good tool to teach basic statistics to attain intended learning objectives for specific learner groups provided that the needs, expectations, the levels of the students, the purpose of the programmed learning, specific learning outcomes are identified accurately.
\end{abstract}

Keywords:- Computer assisted instruction; Distance education; Reflective learner; Statistics education research.

\section{INTRODUCTION}

With the arrival of the microcomputers in the 1970s, the use of computers at schools has become more widespread and has been playing an essential role in instruction, remediation and further guidance in various learning environments ranging from the pre-K to tertiary education or post-graduate education levels (Global Britannica, 2019).

Computer Assisted Instruction (CAI) is the idea that the computer is used as an instructional tool in learning. Instructional material is presented for instruction or remediation with the help of a computer which enhances learning. It is generally used as a tutorial program to reinforce what is learned through question-answer sessions in sequential challenging orders with immediate responses and feedback (Computer Assisted Instruction, 2019).

CAI programs can give learners the opportunity to make a progress at their own pace. The learners can work individually on the presented data/tasks and master the skills required through different types of activities. The learners answer the questions or do the tasks and they are given immediate feedback for what they have not understood thoroughly. They are expected to move ahead until they have got a command of knowledge (Computer Assisted Instruction, 2019).
As part of one of my elective PhD courses in Curriculum and Instruction at Bilkent University, Current Trends and Issues in Educational Technology, I was involved in tutoring sessions about a statistics program called $\mathrm{R}$ on an online portal called Code-School that teaches some subject areas especially the web technologies with video lessons, coding challenges and screencasts. Code-School is an online learning environment that teaches a wide range of programming and web design skills. Learners can take online classes based on their levels such as from the beginner to advanced and earn rewards and badges as they learn through this online learning system.

As a trial, I completed 4 of the 8 chapters compromising the free $\mathrm{R}$ statistical software program on the code-school website. The modules I completed successfully were the first chapter ( $R$ Syntax) was an introduction to $\mathrm{R}$ expressions, variables and functions; the second chapter (Vectors) was about grouping values into vectors and doing arithmetic and graphs with them; the third chapter (Matrices) was about creating and graphing two-dimensional data sets; the fourth chapter (Summary Statistics) was about calculating and plotting some basis statistics such as mean, median and standard deviation.

When I was completing the tasks, my main objective was to reflect on the experiences I gained through the completion of the tasks and critically reflect upon and analyze the effectiveness of CAI through the experience of this statistical program. Therefore, I noted my personal experiences through reflective $\operatorname{logs}$ and evaluated the effectiveness of CAI as an alternative to the traditional learning environment. For my reflective purposes, I did not pay attention to what I learned in basic statistics or mathematics, but elaborated more on my own experiences as a learner and critically analyzed the advantages and disadvantages so as to evaluate the reasons of the use of $\mathrm{CAI}$ as an alternative to traditional instruction.

\section{LITERATURE REVIEW}

In 1954, Skinner was engaged in some studies to advance teaching and learning techniques for some subject areas such as math with the help of a device which would take over the traditional role of a teacher in a regular classroom experience. Hence, Skinner developed an educational theory called "programmed learning" implemented by "teaching machines". This is a technique grounded in behaviorist approach where a learner is provided with information in a sequential order under controlled conditions. (Encyclopedia Britannica, 2019). 
Once the student has grasped the first topic by studying the given information and answering the question(s) correctly, then he/she is given the chance to carry on the next task.

From this point of view, it can be said that the programmed learning is dependent upon steps principle. It is generally regarded as a technique that is "self-paced, selfadministered instruction presented in logical sequence and with much repetition of concepts" and with immediate reinforcement and feedback for the learner (Skinner, 1958). The teaching machine has a program which includes items to be learned that take students from one task to another gradually in sequences. The tasks are generally designed to be fill in the blank method on a workbook or in a computer. If the answer given is correct, the student carries on with the next topic; if incorrect, it requires you to study the topic again until you answer it correctly for increasing the chance of reinforcement. Programmed instruction is based on Skinner's operant conditioning. It is a behaviorist theory which is to do with the idea that learning occurs when there is a change in behavior and behavior is conditioned through rewarding the right stimulus-response patterns.

Prior studies in the literature examined extensively the use of Computer Assisted Instruction (CAI) to develop students' certain skills in other academic courses. For example, Habib, et al., (2019) and Sharifi, et al. (2018) found out that CAI improves students' English language development. Hawkins, et al., (2017) reported that computer-assisted instruction is a curriculum supplement for improving math skills, including math fact fluency. Keengwe and Hussein (2014) reported that students that used computer-assisted classroom instruction gained scores in reading and math. The use of computer applications as a supplement to instruction was also suggested as it promotes student interest and motivation (Macaruso and Walker, 2008).

In addition to the academic courses, students' learning motivations were also studied to explore to what extent computer assisted instruction can act as a means of promoting intrinsic and extrinsic motivation. Gambari, et al., (2016) investigated the role of computer-assisted instruction in promoting intrinsic and extrinsic motivation among Nigerian secondary school chemistry students and found out that students taught with computer simulation instructional package had higher intrinsic and extrinsic motivation.

Studies on computer assisted instruction in the literature varies in terms of the age groups or cognitive abilities addressed by researchers. Some researchers (Trotti, et al., 2017) examined the literacy development of prekindergarten students in literacy development; whereas, Kolpashnikova and Bartolic (2019) conducted a study involving university students about how implementing computer-assisted instructional methods increased their knowledge acquisition in quantitative methods. Furthermore, some studies investigated computer assisted instruction practices for dealing with the special needs of learners (Root, et al., 2017; McKissick, 2017; Mutlu, 2017;
Stultz, 2017) and found out that they provide effective strategies in addressing the learners with certain learning difficulties.

In addition to the studies conducted on the students' enhanced learning outcomes through computer assisted instruction, some other researchers also worked with teachers as research participants to find out their perspectives on the use of computer assisted instruction as a means of enhancing learning or dealing with disruptive student behaviour. For example, Toman, et al., (2013) conducted research to collect the views of science and technology teachers in Turkey about computer assisted instruction, and found out that most of the teachers did not use computer assisted instruction practices in their lessons. Mazzotti, et al., (2012) suggested in their study that computer-assisted instruction could support teachers for classroom management. This study examined the effects of computer-assisted instruction on students' knowledge of the Self-Determined Learning Model of Instruction (SDLMI) and level of disruptive behavior. Results indicated increased knowledge of the SDLMI and decreased levels of disruptive behavior for all participants.

Yet, in my literature review, there was literally no personal reflective exercise about the use of computer assisted instruction with regard to statistics education. Therefore, this reflection paper aims to provide authentic and first-hand reflections on the critical examination of use of computer assisted instruction through online code-school on statistics. This paper will present personal perspectives on the benefits and barriers on the computer assisted instruction from a teacher of English and Theory of Knowledge and as a learner/researcher who was enrolled in a Graduate School of Education for $\mathrm{PhD}$ program in Curriculum and Instruction.

\section{CRITICAL ANALYSIS AND EXAMINATION OF PERSONAL EXPERIENCES}

\section{A. General Reflection on Personal Experiences regarding CAI}

It was the first time I tried such an online learning tool and it was quite useful experience in terms of critical analysis and evaluation of practicality of computer assisted learning tools as an alternative to traditional instruction. I noticed that the Code-School learning portal is very much related with the behaviorist approach in the sense that earning rewards and badges is a direct behavior approach based on Skinners learning theory. It also makes you think of the programmed learning because the online sessions include behavioral objectives, small frames of instruction, self-pacing, active learner response to inserted question and immediate feedback (Skinner, 1958).

My general feeling was that online portals could be regarded as a good means of integrating technology into our educational research and learning and making use of it in a meaningful way for our academic interests, research and learning. As it was self-paced experience and the tasks were ordered in a way that it goes from the easier to the 
challenging, the learners may feel that they are scaffolding their learning in a sequential order and get reinforced with the help of immediate feedback. In a traditional learning environment, teachers may have difficulties in reaching every student to monitor their progress and give constructive feedback individually. Due to the fact that each and every individual has their own pace of learning, the needs and expectations of students in a regular classroom may vary tremendously. Thus, the students in a typical learning environment may lack the reinforcement received from the teacher, which might cause some possible drawbacks such as the loss of motivation, the lack of interest, no demonstration of an ability to make links or associations with what is learned as well as the risk of falling behind and so forth. That's why, I thought that these problems can be limited to moderate extent in computer assisted learning environment by means of providing the learners with the opportunity to take their time at their own pace, go back and revise the parts which were not internalized or grasped thoroughly and get reinforced through the completion of tasks with the personalized constant individual feedback.

Thereby, it can be discussed that the learners' behaviors are constructed with the help of reinforcement of intended learning outcomes. Furthermore, since the content of the sessions were arranged in very small steps, the learners can work on the simple information to master the required skills and challenge himself/herself for a more complex task. However, if the student is stuck with one of the tasks and cannot get what the immediate feedback says or how to act on the identified problem, then there is high probability that learners may feel disappointed and frustrated as I myself did from time to time. It may be demotivating for learners to see that when they put their response to go on the next task, they keep getting warning messages such as "Error: unexpected ... Execution halted" with no other constructive feedback. In this sense, learners may feel that they lose their time in dealing with this type of feedback and concentration while trying to cope with understanding the feedback given.

I personally hold the view that the online sessions may not be of practical use when it comes to the assessment of students' understanding. The reason being is that the information is presented in the designed sequence steps and the material is only checked through some answers to the comprehension type of questions given by the computer. I'd rather I was asked some concept questions, probing questions and review questions so that it checks my understanding fully. Just because you have answered a question correctly does not mean that you have fully mastered this topic. For instance, I have that several of my answers were coincidentally accepted as correct and I went on with the next task with no learning. The tasks do not enhance any higher order thinking skills, but rather one is expected to recall the information and apply it according to the given set of information. This may imply that computer assisted learning does not reinforce higher order thinking skills and it may also not activate learners' prior knowledge and encourage them learning by doing in an effective way.
All in all, although I greatly enjoyed being exposed distance learning through computer assisted instructed on statistics, I felt that shaping students' attitudes and facilitating learning is a complicated process and the tasks designed in orders along with feedback do not expose the learners what they already know or build upon what they are able to learn. It is very limited in the sense that the CAI shows only a good consideration to shape and reinforce responses to be learned. However, learners can benefit from CAI more by means of more varied tasks, effective constructive feedback system, effective praising and rewarding, embedding real life examples, providing further guidance when stuck, needs analysis on the learner types and expectations, activating schemata and building upon prior knowledge and etc. Furthermore, in my opinion, there are some implications for further research about the comparison between CAI and teacher-led traditional instruction in terms of the learned responses being quickly forgotten and computer self-efficacy in online learning and face to face learning environments.

\section{B. Reflections on Benefits and Barriers of CAI}

On the one hand, when I consider the advantages of using CAI, firstly, I can state that as I went through each and every single task in the sessions, I felt that it was user friendly in the sense that it was easy for me to navigate in the system and find any relevant information I was looking for.

Secondly, the programmed learning technique in $\mathrm{R}$ system allowed me to focus on the subject matter under the sequence of controlled steps. Activities were graded in terms of their difficulty levels and this helped me to be motivated at learning the new material since I thought that was encouraged to take my time, focus on the information presented briefly, spend time understanding how it works and what I am expected to do. The easy tasks gave me the feeling that the tasks are doable and the computer would facilitate my learning with its immediate feedback and chance to go back and revise what was not understood.

Thirdly, since I was able to work through the programmed material by myself at my own speed and test my comprehension by answering questions before moving to the next challenging task, I was able to stop, rest, take my time, go back and revise when necessary, which in turn gives the learners some flexibility in their learning.

Fourthly, I felt that it was very time gaining activity because the correct answers were shown immediately and additional information was provided, so as a learner, I did not need to wait for any other learners in a traditional learning environment to slow down my learning with what I already knew or understood.

Fifthly, the specific answers were elicited successfully by the computer. Whenever I made a tiny mistake such as a typo, it warned me and directed me to put the correct response. I believe it is difficult to check each and every single learner's responses and correct their small mistakes 
in a traditional learning environment to avoid any misconceptions or fossilized mistakes.

Lastly, I thought that in a traditional classroom, there is a high possibility that teachers may not work with each and every single student in a crowded class and present them a gradual progression of small units of information and related tasks by providing them with specific situation or stimulus. However, in CAI experience, learners would actively participate in each task by performing the set task, so each student is given a chance for participation as there are no pressure of the time constraints.

On the other hand, when I consider the disadvantages of using CAI, firstly, I should state that the program was not interactive enough. The system was very plain with sets of tasks in order and rigid feedback system. I thought that the concepts could have been better illustrated or delivered through attractive animation, sound and demonstration.

Secondly, the learners may feel frustrated when they are unsatisfied by the feedback provided. Some of the feedback that I received for the tasks that I was not successful made me really angry because I tried all the ways that have come to my mind and I was definitely stuck. The feedback did not make any sense to me from time to time or I did not understand what I was supposed to do. Several times, I felt it was very time consuming spending hours on a single task. For instance, I had problems in figuring out the task: "now see if you can set the value for the 'third' rank to something other than 3 using the name rather than the position" and because there was no way of paraphrasing it or alternative way of explaining it, it took my time to carry on the third session just because of one of the small tasks in the second session.

Thirdly, when I was going through from one task to another, I felt the need for asking questions, getting further guidance or making some associations with the help of a facilitator like a teacher. However, the program only allowed me to progress at my own pace and work individually for the tasks set. I thought that it would have been better if I was also able to work with my classmates or with my teacher for the things I needed further clarifications or how to correctly answer the question.

Fourthly, although I believe that the program offered me a different type of learning experience and learner paced learning instead of teacher-led instruction, it did not play an essential role in guiding the students when necessary. I think learners may need some extra help and support for prompting and hinting in the presentation of the material. The program does not allow the student to proceed with the next task unless you answer it correctly. I do not think that it checks your understanding and ensures that you are qualified enough to carry on the next task. Learners may end up with the feeling of dissatisfaction or frustration when they are not even allowed to proceed. In a traditional learning environment, teachers care about students' attitudes in learning and take the necessary actions to help or guide them.
Lastly, I felt that there is no accountability of learning in this program. CAI programs may foster a student centered learning atmosphere, but teachers ensure that students take active roles and responsibilities of their own learning by monitoring their progress closely and facilitating learning with certain techniques and methods. It is possible that a learner may complete tasks in long time limits unnecessarily or may not be committed to the intended learning outcomes. In a traditional classroom environment, the teacher could counsel students and employ certain strategies to hook up the students' attention and make it more meaningful and useful for the students. However, it is not clear how one can make learners feel responsible and accountable for their own learning progress in such an online learning environment.

\section{Personal Approach to CAI}

I know that this online platform has some limitations which were discussed earlier on, but it also has some insightful ways of approaching the methodological and pedagogical problems in a traditional learning environment. Hence, I would positively consider using this online portal as a teacher to teach basic statistics as long as I would change with the structure of the system in a way that it allows more positive and effective feedback through additional information when things seem unclear, prior knowledge is activated to make connections and more examples are provided when one is stuck. I think I would give this learning experience opportunity for further help and guidance to my students. If I designed the programmed instruction, I would consider specifying the goal of instruction (reinforcement, remedial, further guidance, introduction and etc.) and write the learning objectives more clearly for each module, identify the learners' levels, expectations and needs, make the instruction in small doable flexible steps with more effective feedback, appropriate reinforcement and attractive rewarding system.

I would also consider presenting the material in a more visually appealing navigable structure and provide active learning drills to increase enjoyment of learning. It is also worthwhile to give students formative and summative assessments. For instance, online tutor can give a pre-test for identifying the learners' capabilities and a post-test to assess learners' progress more closely and more accurately and keep the records of the scores to revisit the material when necessary.

Additionally, the online tutor can log in the website to answer specific questions or give further clarifications to the online users. To me, students who are more interested in the technology integration, who do not suffer from anxiety in the use of computers, who prefer more individualistic approach that is self-paced and directed and who need more close immediate individual constructive feedback could benefit from such a statistics education program greatly. 


\section{CONCLUDING REMARKS}

As I worked through the chapters, I tried to explore some of the attributes and capabilities of this online learning technology. I became more aware of the fact that this contemporary e-learning environment can be a means of achieving success in learning if the purpose of this system is clarified, the above-mentioned disadvantages or limitations are acted on, the digital platform allows more flexibility to the learners and more online guidance or support is provided by means of forums, question-answer sessions, video presentations and so on. From this point of view, I hold the view that CAI can be a good instrument to reach intended learning outcomes in statistics education for learners who prefer working at their own pace, need individual immediate feedback, have sufficient computer literacy and who embrace autonomous learner approach.

However, I think it is very important to consider that teachers set the attainable objectives and the purpose of the programmed learning clearly, do a needs analysis to structure the online portal more effectively by designing it according to the students' levels, interests, expectations and needs. If CAI serves for reinforcement, enhancement or enrichment of learning and greater learner autonomy, I believe it should be more flexible in terms of feedback, the presentation of material and review-revision.

There is also a need for further research based on the implications discussed with regards to how the online portal can be shaped in a way that it may foster higher order thinking skills such as analysis, synthesis and evaluation in statistics education based on the learners' feedback and their own reflections on their experiences with CAI.

\section{REFERENCES}

[1]. Computer Assisted Instruction and Reading. Retrieved from http://www.readingrockets.org/article/4185 Last access 12.11.2019

[2]. Code-School. Retrieved from https://tryr.codeschool.com/ Last access on 31.03.2019

[3]. Encyclopedia Britannica Programmed Learning. Retrieved

from

https://www.britannica.com/topic/programmedlearning\#ref12911 Last access 30.03.2019

[4]. Gambari, I. A., Gbodi, B. E., Olakanmi, E. U., \& Abalaka, E. N. (2016). Promoting Intrinsic and Extrinsic Motivation among Chemistry Students Using Computer-Assisted Instruction. Contemporary Educational Technology, 7(1), 25-46.

[5]. Global Britannica, Computer Assisted Instruction. Retrieved from https://www.britannica.com/topic/computer-assistedinstruction Last access on 12.11.2019

[6]. Habib, M. A., Mustapha, M. A., \& Ali, H. (2019). Use of Computer Assisted Instruction to Improve Students' Reading Skill in English Language. Journal on English Language Teaching, 9(1), 32-37.
[7]. Hawkins, R. O., Collins, T., Hernan, C., \& Flowers, E. (2017). Using Computer-Assisted Instruction to Build Math Fact Fluency: An Implementation Guide. Intervention in School and Clinic, 52(3), 141-147.

[8]. Keengwe, J., \& Hussein, F. (2014). Using ComputerAssisted Instruction to Enhance Achievement of English Language Learners. Education and Information Technologies, 19(2), 295-306.

[9]. Kolpashnikova, K., \& Bartolic, S. (2019). Digital Divide in Quantitative Methods: The Effects of Computer-Assisted Instruction and Students' Attitudes on Knowledge Acquisition. Journal of Computer Assisted Learning, 35(2), 208-217.

[10]. Macaruso, P., \& Walker, A. (2008). The efficacy of computer assisted instruction for advancing literacy skills in kindergarten students. Reading Psychology, 29, 266-287.

[11]. Mazzotti, V. L., Wood, C. L., Test, D. W., \& Fowler, C. H. (2012). Effects of Computer-Assisted Instruction on Students' Knowledge of the SelfDetermined Learning Model of Instruction and Disruptive Behavior. Journal of Special Education, 45(4), 216-226.

[12]. McKissick, B. R., Diegelmann, K.M., \& Parker, S. (2017). Using Technology to Address Barriers in Rural Special Education for Students with Autism: A Do-ItYourself Guide. Rural Special Education Quarterly, 36(3), 155-159.

[13]. Mutlu, Y., \& Akgün., L. (2017). The Effects of Computer Assisted Instruction Materials on Approximate Number Skills of Students with Dyscalculia. Turkish Online Journal of Educational Technology, 16(2). 119-136.

[14]. Root, J. R., Stevenson, B. S., Davis, L. L, Geddes-Hall, J.., \& Test, D. W. (2017). Establishing ComputerAssisted Instruction to Teach Academics to Students with Autism as an Evidence-Based Practice. Journal of Autism and Developmental Disorders, 47(2), 275-284

[15]. Skinner, B. F. (1958). Teaching machines. Science. 128(3330), 969-977.

[16]. Stultz, S. L. (2017). Computer-Assisted Mathematics Instruction for Students with Specific Learning Disability: A Review of the Literature. Journal of Special Education Technology, 32(4), 210-219.

[17]. Sharifi, M., Rostami A., Ali, A., Jafarigohar, M., \& Zandi, B. (2018). Retrospect and Prospect of Computer Assisted English Language Learning: A Meta-Analysis of the Empirical Literature. Computer Assisted Language Learning, 31(4), 413-436.

[18]. Toman, U., Gurbuz, F., \& Cimer, S.O. (2013).The View of Science and Technology Teachers about Computer Assisted Instruction. Mevlana International Journal of Education, 3(2), 77-87.

[19]. Trotti, J., Hendricks, R., \& Bledsoe, C. (2017). Emergent Literacy Development and Computer Assisted Instruction. SRATE Journal, 26(1), 30-39. 